\title{
LIX. Method of producing heat, light, and various useful articles, from pit coal
}

\section{Mr. B. Cook}

To cite this article: Mr. B. Cook (1811) LIX. Method of producing heat, light, and various useful articles, from pit coal , Philosophical Magazine Series 1, 37:157, 332-339, DOI: 10.1080/14786441108563298

To link to this article: http://dx.doi.org/10.1080/14786441108563298

曲 Published online: 18 May 2009.

Submit your article to this journal $[\pi$

Џ Article views: 2

Q View related articles $₫$ 
quired. The weight of the counterpoise will be most easily found by experiment. If it be too little, it will correct the evil in part but not entirely; the bellows will therefore still yain some force as they fall. If again the counterpoise be too great, the bellows will have most force when full, and will gradually loze force as they fall. - In testimony whereof, \&c.

LIX. Method of producing Heat, Light, and various useful Articles, from Pil.Coal. By Mr. B. Cook, of Birmingham*.

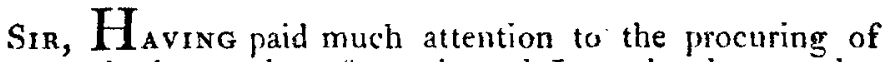
gas and other products from pit-coal, Inow beg leave to lay before the Society for the Encouragement of Arts, \&c. the results of some of my experiments on pit-coal, and the methods of procuring the sundry articles of which I have sent samples, and a japarnerl waiter varnished therewith. The quantity of clear tar which may be produced from every hundred weight of coal is about four pounds, from which a liquor, or volatile oil, may be distilled, which answers the purposes of oil of turpentine in japanning. Every gallon of tar will produce nearly two quarts of this oil by distillation, and a residuum will be left ncarly, if not quite equal, to the best asphaltum. I have sent a waiter, or handboard, japanned with varnish made from this residuum, and the volatile oil above mentioned. This dries sooner, and will be found to answer as well as the best oil of turpentite, a circumstance which will be of immense advantage to this country, as in the vicinity of Birmingham only, nearly ten thousand tons of pit-coal are coked or charred per week ; and all the tar hitherto been lost; but by my process, I dare venture to say, that from the various coal-works in this kingdom, more tar might be produced than would supply all our dock-vards, boat-builders, and other trades, with tar and pitch, besides furnishing a substitute for all the oil of turpentine and asphaltum used in the kingdom, and improving the coke so as to make iron with less charcoal.

I have sent a large specimen of the asphaltum, and three vial bottles containing as follows :

No. 1.-A sample of the oil or spirit, being part of that

* From Trausartions of the Society for the Encouragement of Arts, Manufactures, and Commerce, for 1810. The Society vuted their silver medal to Mr. B. Cook for this invention. 
which was used in making the varnish with which the waiter sent was japanned.

No. 2.-Is the same oil or spirit, a little more rectified.

No.3.-The same, still further rectified, and of course more clear, and freer from smell ; but $I$ find that the specimen, No. 1, answers quite as well for varnish.

Tar spirit is now about $8 s$. per gallon, and turpentinespirit about 15s. This latter has been, within the last two years, as high as $48 s$. per gallon, and the tar-spirit will answer equally well for varuish, on using the coal-tar-spirit, instead of the turpentine-spirit.

I requested Mr. Le Resche to use the tar-spirit just in the same way he would the foreign spirit, and theh give the varnish to his work-people to use, without making any remark to them, which was done: he making the varnish himself, found it mixed, and made the varnish as good in appearance as that prepared with the foreign spirit. He then gave the varnish to his work-people to use; and when they had finished their work with it, he found from their report, that it answered perfeetly, and dried sooner; and when the waiter done with it was given to the polisher, it was found to polish much smoother under the hand, and take a more beautiful gloss than their former varnish, as the article now sent will show on inspection.

I am of opinion that the production of these articles will be of great public service. Permit me to add, that the timber of ships paid with this tar is not nearly so liable to be worm-eaten as those done with common tar.

$$
\begin{aligned}
& \text { I remain, sir, } \\
& \text { Your humble servant, }
\end{aligned}
$$

Birmingham, Jan. $12,1810$.

B. Cook.

To C. Taylor, M.D. Sec.

Reference to $M r$. Cook's Apparatus' for preparing Gas and other Prouluts from Pit-Coal, Pl. 3.

A, Fig. 1, Pl. VIII, is a common fire-place, a stove built with brick, having cast-iron bars to put the fire in at, and a flue that goes into a chimney; $A$ is the cast-iron pot, (which holds from twenty-five pound to one hundred pound of coal, according to the size of the premises to be lighted) which hangs by the bewels or ears on a hook, suspended by a chain in this stove or furnace, about three inches above the bars of the grate, and three inches distant from the sides of the stove; the fire then flames all round this pot, and as it does not rest on the burning fuel, it is the flame only 

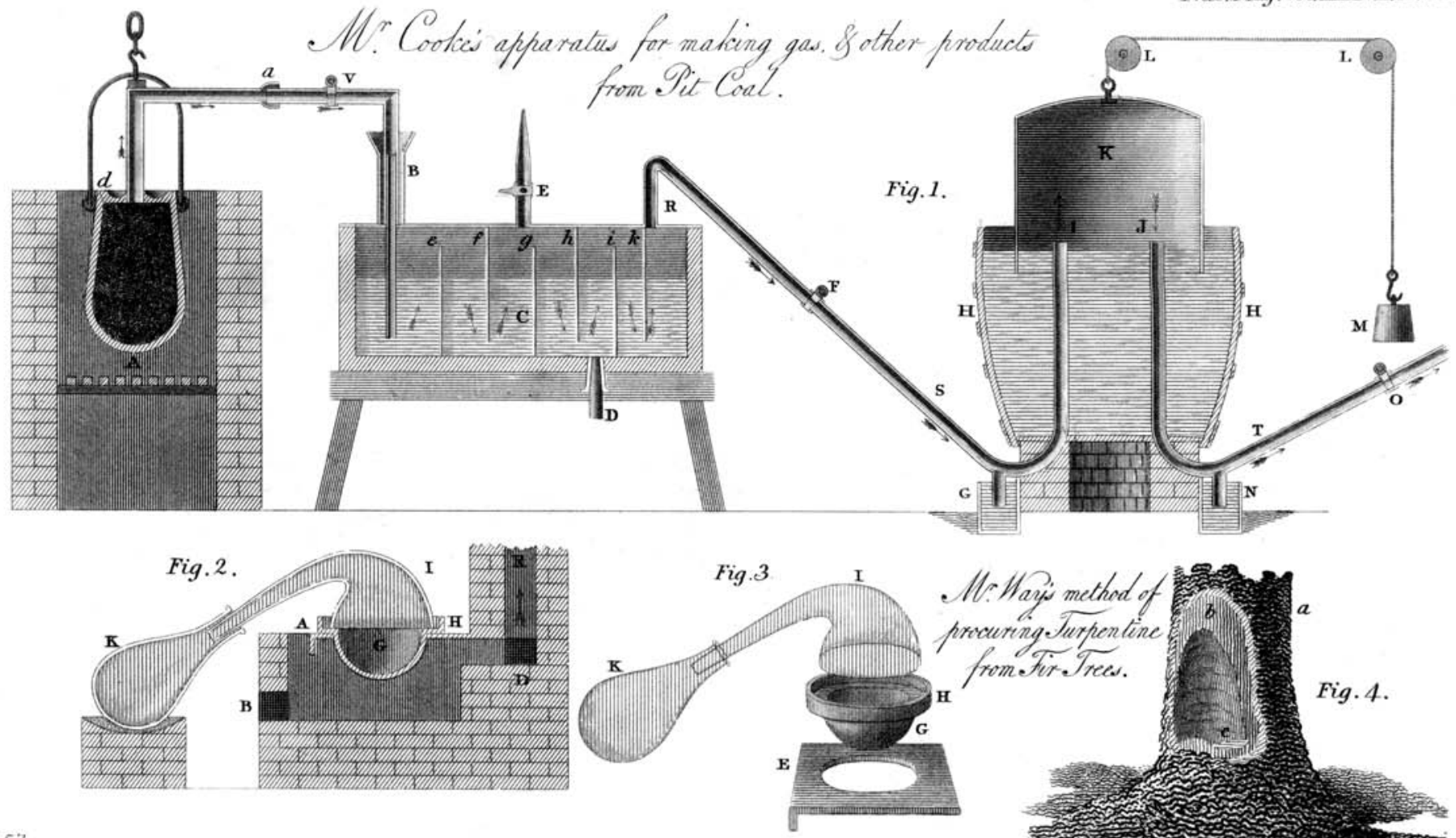
that heats it, so that it does not scale, but will last for years. The smoke, \&zc. is carried off into a chimney. The cover $d$ of the pot is made rather conical, to fit into the top of the pot close, and from the top of the cover the elbow-pipe proceeds as far as the mark $a$. The other end of the pipe with the elbow entering the water-joint is rivered to it after ; when the lid or cover of the pot is put on, the bewels or ears come over the elbow of the pipe that is on the lid, and a werge is put between them and this elbow, to keep down the cover air-tight, and a little clay or loam may be luted in the joint, if any gas should escape round the cover of the pot. The other elbow $B$ goes into a water-joint, formed of a tube affixed to the cover of the purifier $\mathrm{C}$; and another tube, which passes through the lid of the purifier: the elbow-pipe then goes over the inner tube, and when put on, the jointing is made gond by pouring water into the space between the tubes, which renders it air-tight. The gas, as the arrows show, passes down into the purifier $\mathrm{C}$, which is rather more than half full of water; the use of this water-joint is for the convenience of removing the lid $d$, to which this pipe is attached. The purifier $\mathbf{C}$ is a wooden trough, with a sheet-iron top, to which the tubes are soldered, and it is fastened to the trough to keep all secure and air-tight. The sheets of iron, $e, f, g, h, i, k$, are alternately soldered to the iron top, and fastened to the wooden bottom. Now when the trough is half filled with water, the gas passes into it at $\mathrm{B}$; and as it can only find its way out again at $R$, it must pass tbrough the water. The inner pipe $B$ reaches under the surface of the water in the trough; now when the gas is forced into the water, it would rise to the top of the purifier, and go along in a body to the end, and out at the pipe $\mathrm{R}$, if the sheets of iron, $e, f, g, h, i$ and $k$, which stand across the trongh with openings in them, alternately at top and bottom, did not stop it, furce it to descend down into the water, and hinder it from going any way but through these apertures, purifying it all the time it is passing through the whole body of water, until it is properly washed: it then escapes through the pipe $R$ at the end of the trough $C$, then passes down the pipe $S$, and is carried up into the reservoir or gazometer $K$. In the bottom of the purifier is an aner:ure, closed by a plug at $D$, to let off the ammoniacal water and tar as it is deposited, and the pipe, with the cock $\mathrm{E}$ at the top of the purifier, is to burn away the spare gas when not to be used.

There is a stop-cock placed in the main pipe at $F$, that when 
when the reservoir is full, and gas is making, and cannot be used, the cock may be turned, and prevent any gas from passing from the reservoir; and by opening the cock $E$ on the top of the purifier, and firing it, all the gas which is made more than is wanted for use may be burnt away. If this was not done, the gas would continue to find its way into the reservoir $\mathrm{K}$, which would overflow, and produce a disagreeable smell, which this simple way of burning it away as fast as it is made when not wanted, prevents.

It may in some measure happen, that although the gas has passed through the purifier $\mathrm{C}$, yet that a small portion of tar will pass along with it, and would either clog the pipe $S$, or accumulate in the reservoir. To avoid this, there is placed at the bottom of the pipe $S$ at $G$, before it rises into the reservoir, a jar into which a pipe made, as shown in the cirawing, conducts the tar ; this collects all that passes through the purifier; it is flled with water, over which the gas passes up into the reservoir, but the tar drains down this fead pipe and deposits itself in the jar of water. The longer this pipe $S$ is, the better, as it serves as a refrigeratory. $H$ is a plain cask, made to any proper size, and filled with water, with a cock to draw off the water when it becomes foul. The upper vessel $\mathrm{K}$ is made of sheet iron, riveted together in the uranner engiue-boilers are made. If it is only from five hundred to one thousand gallons in size, it will require only two cross iron bars at top, and four ribs down the sides to keep it in form, with a strong ring at top; and as there is no stress on this vessel, it will ascend and descend easily without any other support or framing, the plain sheet iron sides being riveted to the fuur ribs, and it is quite open at the bottom. A strong rope runs over the pulleys L L, with a weight $M$ to balance the vessel $K$, and assist it in rising and falling. The pipe $J$ is that through which the gas passes from the reservoir or gazometer, and rising through the pipe $\mathrm{T}$, is conveyed to all parts to be lighted. There is also another drain pipe at $\mathrm{N}$, for after all the washing, 8xc. a very small portion of tar and moisture may rise into the pipes, and perhaps in time clog them; but by laying all the pipes in the first, second, and third stories on a small descent, if any tar or moisture should rise, it will drain down all the pipes from top to bottom, and be deposited in the earthen jar at $\mathrm{N}$ : by that means the pipes will not clog up in half a century. These jars must be sometimes removed and emptied, fresh water put in, as also the water in the vessel $\mathrm{H}$ must be changed, to keep it clean and sweet; and the water in the purifier $\mathrm{C}$ 
should be changed every two or three days: by these means the gas will be deprived of all its smell, at least as far as washing will effect it, and the apparatus will be clean.

The stop cock at $O$ is for the use of a master, if he wishes to lock up the gas in the reservoir, to prevent his workman, \&c. wasting it in his absence; as also if any pipe should leak, or a cock be out of order, in any part of the premises, by turning this cock all the gas is kept in the reservoir while the pipe is repaired, or any other alteration made; it also extinguishes all the lights when turned, if any are left huruing by careless workmen, nor can they be lighted until it is opened again.

The whole of this apparatus is simple, and not liable to be put out of order in such a way, but that any person may put it to rights again. All the art required to make the gas is to take off the cover of the pot, and without removing the pot to take out the coke, and fill it with fresh coal, wedge it down by putting an iron wedge between the bewels or ears and the elbow of the vessel, and if required, plaster a little clay or loam round the cover, to keep it air-light; a fire is then made under it, and the whole is done. The hoy or man who does it, must now and then look at the fire and keep it up, until the pot is hot, and the gas is made. Now in works where lights are wanted almost always, I would recommend two fire-places, and two pots, so that when one pot is burned out, the other pot may be ready to act; for this purpose the purifier must be provided with two of the water-joints $B$, one communicating with each pot, and the elbow pipe of each pot must have a stop-cock, as $V$ : now when one pot is burning, the cock in the other pipe must be stopped, that the gas may not find its way out of the purifier; ard when all the gas is extracted from that pot, the cock $C$, leading from it, must be stopped, and the pot left to cool; while a fire is put under the other pot, its cock is opened, and a supply of gas from it is passed into the reservoir: by these means one of the pots is constantly supplying the reservoir with gas, and the lights are always kept buruing; one purifier is all that is necessary: the $c \mathrm{ck}$ $V$ must be shut when either of the covers is iaken up to fill the pot again with coal : when the elbow pipe is lifted out of the water-joint, as the cover is attached to it, a plug nusi be provided to fit into the water-joint pipe the moment the elbow is removed from it, or the gas will rush out of the pipe at the water-joint; but a better way would be, to lengthen the pipe of the water-joints $B$, and place a large 
cock under each of them, almost close to the top of the purifier; when one pot is burnt out by turning the cock it keeps all the gas in the purifier while the cover is removed: no plug is necessary in this method. When people are very particular, (especially when houses or accomptinghouses are to be lighted, and wish all smell to be destroyed, if they are not satisfied with washing it, and still think there is a little smell left, (and very little indeed, if any, will be left;) after the washing, a small trough may be added, made in the same way as the purifier, with sheets of iron across to force the gas through the pipe $\mathrm{R}$ communicating with it. This trough may be filled with water, with a few lumps of lime put into it, and this water and lime changed ofter. On the gas being forced through this lime-water, if there was any remaining smell in it, this would completely take it away; and, as has been before observed, by changing all the waters now and then, and keeping this small trough constantly supplied with clean water and lime, the gas afier passing it will ascend the pipes to the lights pure.

Sir,-Having been from home, I was prevented from answering your obliging letter until this day.-I am much pleased that the Society have approved of my specimens produced from pit-coal. I feel also highly gratifed and honoured with their reward. I hope to lay before you, in a short time, an account of the establishment of a work that will be of such magnitude, as will supply this part of the country with the oil or spirit, in sufficient quantity to supersede the use of turpentine, \&c. in japanning; and I do hope that in time works of the same description will be established through all Staffordshire, whose products will supply the place of a great portion of the spirit used in the kingdom, while the pitch will be of sufficient quantity to form a great part of that article now used in the dock-yards.

All I want is support from the great coal companies and masters, to erect sufficient apparatus at the different works to preserve the tar at all the coke furnaces, and proper means to separate the spirit from the tar. It would be a great saving to the nation; as in every one hundred and twelve pounds of coal coked, there is lost by the present mode about four pounds of tar, and the cokes are not half so good as it they were coked in close vessels, to the exclusion of the atmospheric air. I need not describe the method by drawings of the manner of extracting the tar from pit-coal in Vol. 37. No. 157. May 1811. close 
close vessels, as that method is so generally known; it must be clear to every one, that it is procured by distilling the coal.

I have, as follows, described the method I use in extracting the spirit from the tar, the process of which is so simple that every one must understand it.

Fig. 2, Pl. VIII. is a section of the furnaces, and one of the retorts, almost auy number of which may work in a line; the same flue will do for all, only taking care, if any are not at work, to stop up the draught-bole, which communicates with the flue. These furnaces are built without bars, grates, or doors. A is the place where the fuel is put in to heat the retort $\mathrm{G}$; the fire lies under it, and the smoke is carried off into the flue $F$. $B$ is the aperture where the ashes are raked out. $G$ is a section of the iron bason, or lower part of the retort; the dark-shaded square part shows the space the fire occupies, and the black square $D$ the flue as it runs along the back of all the line of furnaces, and enters the chimney $R$, as the arrows show. I, figs. 2 and 3 , shows the upper part of the iron, earthen, or glass retort, fitted on the cast-iron bason G. $K$, the receiver. By this mode of setting the retorts, all the great expense of bars, doors, frames, \&c. is saved, and a brisker draught of air is obtained, which may be slackened at pleasure by covering up in part, or wholly, the fire-place $\mathbf{A}$ with a brick. $\mathbf{E}$ is a square iron plate with a circular hole in the centre, built on the top of the furnace. The cast-iron bason of the retort $G$ is made to the size of the hole in the plate: the most convenient size of the bason of the retort 1 find is about five or six gallons, in the shape of a deep pot, with a flanch or rim $\mathrm{H}$ round the edge of it; this pot or bason of the retort is put into the iron plate $\mathrm{E}$, and the flanch of the retort then rests on the plate $E$. I is the upper part of the retort without a bottom, made to rest and fit on the flanch of the cast-iron bason $G$. $K$ is the receiver, larger in the mouth than the nose of the retort. To begin the work, I fill, nearly, the iron bason of the retort $G$ with coal-tar. I then put on the upper part of the retort $I$, and make it airtight with a little sand thrown round it at the flanch $\mathrm{H}$; the receiver $\mathrm{K}$ is put in its place, and a slow fire is put in at $A$, under the retort: the tar soon begins to boil slowly, or rather simmer. Now as soon as that begins there rises from the tar a thick whitish vapour, which fills the glass retort, part becomes condensed, and falls in drops from the sides of the returt into the tar again, while the purer spirit rises into the neck, is condensed, and keeps dripping down 
the neck into the receiver: this is the spirit of the tar, and with this spirit that first arises from the tar was the waiter japanned which I sent you. The reason I chose to have the receiver wider at the mouth considerably than the nose of the retort is, that there is a strong and very volatile oily ammonia, that does not sonn condense, but gets out of the receiver into the air the instant it leaves the retort, and though but in a very small quantity, so small that it is hardly possible to catch it; yet will it impregnate the air for a great distance round, with its very penetrating smell, while the spirit keeps dropping into the receiver pure and separate from the ammonia. The spirit is very volatile, quite as much so, if not more, than the spirit of turpentine, and soon evaporates if exposed to the air, which is a proof of its drying nature; indeed when used as a substitute for turpentine, it dries in the stove quite as soon or sooner, and takes equally as beautiful a polish. I sent you three specimens. No. 1. is what came off the tar first. No. 2. is the same distilled a sccond time; and the third specimen is the second re-distilled again in a glass retort: it there leaves a little pitchy residuum, and comes over clear, as the sample. Very little of the spirit is lost in passing through these different stages, if care is taken that the fire is slow and the process not hurried. When the spirit is perfectly extracted from the tar, there remains in the bason of the retort that beautiful pitch or asphaltum sent, which when mixed with the spirit forms an ingredient for making the black varnish used in japanning. If it is wished to use it as pitch, less spirit must not be extracted from it. I find that six gallons of tar will produce, if care is taken, about two gallons or two gallons and a half of spirit. A great number of retorts nay be kept working by a single man; if we say only one hundred, and only worked down in a day, they will produce two hundred to two hundred and fifty gallons of spirit, so that, by increasing the number, any quantity may be obtained. When the spirit is used in the place of turpentine, the varnish-maker uses it in the same way, and in the same quantity, as there appears no manuer of difference in the use of it from spirit of turpentine in the making of varnish. When the asphaltum is used, it supplies the place of real asphaltum, and in about the same quantity. I have explained the whole as clear as I can; but if any more information is required, I should feel happy in giving it, and am, sir, with great respect,

Birmingham, March 1s, 1810.

Your obedient humble servant,

To C. Taylor, M.D. Sec.

Y 2

B. Cook.

LX. Com- 